\title{
Calidad periodística y fuentes presidenciales: el periodismo argentino frente a la comunicación de gobierno
}

\author{
Adriana AMADO \\ UNLAM (Buenos Aires - Argentina) \\ amadoa@catedraa.com.ar
}

Recibido: 5 de diciembre de 2014

Aceptado: 8 de mayo de 2015

\section{Resumen}

La diversidad de voces es un parámetro de calidad periodística que excede la decisión del periodista en tanto depende de la disponibilidad de las fuentes. El caso argentino ilustra cómo impactan en el periodismo los límites al acceso a las fuentes oficiales y a la información pública impuestos desde la oficina de prensa de Presidencia de la Nación. Este artículo revisa el contexto del vínculo entre los periodistas y las fuentes presidenciales desde 2001 en Argentina, enfocándose en el análisis de las restricciones que impuso el Poder Ejecutivo a las conferencias de prensa.

Palabras clave: periodismo, calidad periodística, fuentes oficiales, conferencia de prensa.

\section{Journalism Quality and Official Sources: Argentine Press and Government Communication}

\begin{abstract}
The sources diversity is a journalism quality indicator but it is not only the result of journalist decision as it depends of the sources availability. Argentine case shows how Argentine Presidential Press Office increasingly reduced the access to public information and official sources. This paper reviews the context for the relationship between journalists and presidential sources in Argentina in order to analyze the influence of the public officers'restrictions to the press conferences.

Keywords: journalism, quality journalism official sources, press conference.

\section{Referencia normalizada}

AMADO, Adriana (2015): “Calidad periodística y fuentes presidenciales: el periodismo argentino frente a la comunicación de gobierno". Estudios sobre el Mensaje Periodístico. Especial noviembre "Periodismo e información de calidad", págs.: 63-84. Madrid, Servicio de Publicaciones de la Universidad Complutense.
\end{abstract}

Sumario: 1. Planteamiento: Periodismo sin fuentes. 2. Contexto: Periodismo sin iniciativa. 3. Análisis: Periodistas sin preguntas. 4. Discusión: Periodismo sin calidad. 5. Referencias bibliográficas.

\section{Planteamiento: Periodismo sin fuentes}

La variedad y autoridad de fuentes es un indicador de la calidad de la cobertura periodística en la medida en que constituye el respaldo de la información (Gans, 1979). De ahí que "el acceso a fuentes fiables y la equidad que se establezca entre ellas en cada noticia, constituyen un valor noticioso y un factor determinante respecto de la calidad de la información" (De la Torre at al., 2007: 54). Sin embargo, es una variable que no depende únicamente de la redacción porque es sensible a factores externos como las restricciones al acceso a las fuentes o el desequilibrio derivado del hecho de que las fuentes de poder político y económico tienen más posibilidades de influir en la cobertura que otros actores sociales. 
Los actos y declaraciones de los presidentes son parte ineludible de la cobertura noticiosa que resulta de una relación en la que el mandatario tratará de controlar los medios y los periodistas intentarán ir más allá de lo que el presidente quiere declarar (Shoemaker y Reese, 1996: 173). El caso argentino permite analizar este juego de tensiones al mostrar cómo impactan en el periodismo las restricciones que se imponen al acceso a la información pública. Desde la crisis institucional de 2001, la estrategia presidencial se basó en una intensa campaña de difusión y propaganda acompañada con la decisión de limitar el contacto directo de los funcionarios con la prensa, lo que generó una tensa relación con los medios y los periodistas (Amado, 2010, 2011; Waisbord, 2013b; Ruiz, 2014).

Desde que Néstor Kirchner asumió la presidencia en 2003, restringió los contactos con los periodistas para concentrar la información en el diario de mayor circulación del país al que beneficiaba con exclusivas y trascendidos (Mochkofsky, 2011; Ruiz, 2014). Su sucesora y esposa, Cristina Fernández, decidió comunicar exclusivamente a través de sus discursos y mensajes institucionales, por lo que redujo las entrevistas y conferencias de prensa, que solo brindó principalmente a medios internacionales y a unos pocos locales. La información oficial desde entonces es producida por agencias que dependen de la Secretaría de Comunicación Pública. Las imágenes, discursos y comunicados se difunden a través de espacios virtuales, agencias de noticias y medios institucionales (Amadeo et al., 2013). La prensa, con excepción de los medios estatales y algunos otros de afinidad manifiesta al partido gobernante, no tienen acceso a las actividades oficiales, por lo que cubren los eventos a partir del material producido por una productora privada al servicio de Presidencia de la Nación desde 2004.

Otra característica del estilo presidencial es que los voceros no hacen declaraciones a la prensa. Miguel Núñez ocupó el cargo de vocero de Néstor Kirchner desde 2003 y continuó en funciones con Cristina Fernández hasta agosto de 2009, cuando se disolvió la Unidad de Comunicación Presidencial "a fin de dar una rápida respuesta a las necesidades de la gestión comunicacional", según dice la resolución (Decreto 1156/2009, 2009: web). A partir de entonces el rol fue ocupado por el Secretario de Comunicación Pública, Alfredo Scoccimarro, de quien depende la subsecretaría que manera las direcciones de Fotografía, de Sala de Conferencias y Registro Audiovisual y de Difusión Presidencial. A diferencia de su antecesor, eventualmente ofició de vocero a través de la lectura de comunicados.

En este esquema los medios se dedican a difundir y comentar las imágenes producidas por la secretaría sin posibilidad de participar en los eventos oficiales ni tener interacción con los funcionarios. La comunicación pública así digitada representa una "constricción de la mediación periodística, que se ve fuertemente restringida y obstaculizada por las prácticas operadas por los actores políticos" (Casero-Ripollés, 2009: web). Cuando son las fuentes las que deciden las circunstancias y condiciones en que se informa, se instauran rutinas periodísticas dependientes de la información oficial y se entorpece el control de la prensa de las cuestiones de interés público (Livingston y Bennett, 2003: 368). Ello se agrava cuando periodismo y medios son blanco de críticas y presiones de los funcionarios, en las que justifican su decisión de no atender a la prensa. 
Una restricción para cubrir la información oficial es la decisión de Presidencia de limitar las ruedas de prensa desde 2003. La conferencia de prensa presidencial es una interfaz del ejecutivo con los medios que transparenta la relación entre los periodistas y el gobierno en la medida en que hablan directamente con el mandatario y no solo escriben de él (Clayman et al., 2007: 26). La conferencia de prensa es un espacio público de construcción de información y un ejercicio del periodismo de control tan efectivo como el clásico periodismo de investigación pero mucho más dinámico (Clayman et al, 2007: 36). Por tratarse de un evento público donde participan varios periodistas a la vez, se convierte en una instancia más equilibrada de comunicación, dado que las entrevistas personales o los trascendidos que concede el funcionario ponen al periodista en un lugar subsidiario de la voluntad política en un vínculo poco transparente para la ciudadanía.

La posibilidad de interrogar a los funcionarios más allá de la información de difusión se vuelve crítica cuando se cierran los canales de acceso a la documentación pública, otra vía de control de las actividades gubernamentales para el periodismo. En Argentina no existe una ley de acceso a la información pública y el decreto presidencial que lo habilita no promovió el uso periodístico en función de la demora en la respuesta y el irregular acatamiento en los distintos organismos. Según los datos disponibles, los periodistas representaban menos del $4 \%$ de los pedidos formulados por esta vía, aunque se habían triplicado en cantidad desde 2004 a 2008 (Amado, 2010: 112). El organismo responsable dejó de producir sus informes en 2008 y la asignada por la Jefatura de Gabinete de Ministros al acceso a la información está desactualizada (ADC Acción por los derechos civiles, 2013: 3).

Esta situación particular da cuenta de una tendencia global que obliga al periodista a redefinir su posición frente a las fuentes de poder y la forma en que producirá la información que involucra a estos actores de relevancia para la sociedad. La creciente profesionalización de las fuentes institucionales (Blumler at al., 1999) fue demandando nuevas actitudes del periodismo para responder a intentos de control de las fuentes tales como limitar los contactos con la prensa o convocar a conferencias de prensa donde no es posible hacer preguntas (Humanes et al., 2013: 728). O, como ocurre con varios presidentes latinoamericanos, negarse abiertamente a atender a los periodistas o los que hostigan por diversas vías (Rincón, 2008; Waisbord, 2013b).

La propuesta de este artículo es analizar datos secundarios y publicaciones de actualidad para describir el contexto en que se estableció el vínculo entre las fuentes presidenciales y el periodismo argentino a partir de 2001. A partir de los datos disponibles, se busca describir las instancias de contacto de la prensa con presidencia de la Nación y las condiciones del periodismo argentino, a fin de contextualizar las iniciativas tomadas por medios y periodistas para resolver las restricciones ${ }^{1}$. Las restricciones a las conferencias de prensa impuestas por el ejecutivo y la debilidad de las iniciativas de los periodistas para enfrentar esa limitación dan cuenta de las circunstancias en que se desarrollan las relaciones informativas en Argentina y muestra el proceso por el cual el sistema de comunicación pública ha limitado la participación del periodismo.

${ }^{1}$ El trabajo forma parte del proyecto "Factores de influencia y los actores participantes en la construcción de la información pública” (PROINCE 55 A180, UNLAM). 


\section{Contexto: Periodismo sin iniciativa}

La negativa de acceso es una forma corriente de ejercicio de poder de parte de la fuente (Gans, 1979: 174) y la capacidad reacción del periodismo ante esa acción da cuenta del modelo profesional vigente y su estrecha vinculación con el contexto y con los otros campos sociales (Waisbord, 2013a: 12). La creciente profesionalización de la comunicación no es un fenómeno exclusivo de las fuentes institucionales, sino que se observa también en personas, grupos, movimientos sociales y organizaciones que utilizan la estructura de producción, circulación y consumo de información "para imponer, gestionar y hacer más eficaces sus reclamos, pedidos y presiones y su consolidación como fuentes principales de las noticias" (Fernández Pedemonte, 2010: 79). Sin embargo, es el poder de las fuentes junto con la necesidad que de ellas tienen los periodistas, lo que las legitima para intervenir activamente en un proceso que se ratifica a sí mismo: las fuentes de rutina suelen ser más y mejor tratadas en la prensa, no sólo porque se dedican al manejo de las noticias y saben controlar cómo aparecen en público, sino porque su posición les permite una relación estable con los periodistas (Sigal, 1973; Gans, 1979).

Aunque no existen en Argentina investigaciones sistemáticas sobre la influencia de las fuentes oficiales, diversos trabajos señalan su preponderancia en la cobertura. Un estudio sobre calidad periodística de diarios nacionales detectó que un $59 \%$ de las noticias analizadas proviene de informaciones entregadas o producidas por la fuente y solo un $27 \%$ se originaron por iniciativa del medio (De la Torre y Téramo, 2004: 70). Las fuentes gubernamentales y públicas representaban el 29\%, la mayoría del $38 \%$ de las fuentes institucionales en los diarios nacionales, proporción que se mantenía en un diario regional en el 27\% del 37\% (Téramo, 2006: 41). De la ponderación de los indicadores de selectividad y de acceso la investigación concluye que existe una dependencia de las fuentes y un predominio de los testimonios personales sobre las fuentes documentales. Las conclusiones sostienen que la iniciativa de los comunicadores institucionales viene a responder a la presión de llenar unas páginas en tiempo restringido, con lo que no son solo los eventos "novedosos o investigados en su profundidad los que se imponen por su propio peso a la lógica informativa, sino aquellos atractivamente propuestos con antelación, a través de agencias informativas, fax directos a la redacción o llamados al periodista" (De la Torre y Téramo, 2004: 67). Los estudios que realizó la organización Periodismo Social sobre las noticias de niñez e infancia confirman la participación mayoritaria de las fuentes gubernamentales en 2008 (59\%) y 2009 (44\%) (Cytrynblum, 2008, 2009).

En este contexto, la información que involucra a las fuentes de poder, si además está presentada y disponible convenientemente se convierte en un material con alta probabilidad de ser publicado. Aun cuando la información institucional sea de baja calidad periodística como concluyó una encuesta a periodistas argentinos, que señalaban que la información de los gabinetes de prensa es poco noticiable o muy publicitaria; y se quejaban de que los relacionistas desconocían los intereses del medio y del periodista y los procesos de la redacción (Pizarro et al., 2008: 28). Los periodistas indicaban, como principales problemas del vínculo con los jefes de prensa, la falta de interlocutores adecuados para ampliar información, demasiados envíos de material o 
profusión de invitaciones, así como la insistencia para obtener la publicación. Esta tendencia general se confirma en el caso de la información gubernamental, donde la intensa oferta tiene como contracara obstáculos para la demanda: poca accesibilidad de los periodistas a los informantes claves, ausencia de voceros dispuestos a dar declaraciones en los tiempos periodísticos y la falta de un marco legal que garantice el acceso a información pública (Lavalle y Schmidt, 2009).

A la adecuación a los procesos noticiosos hay que agregar las presiones directas de las máximas autoridades que van desde la recriminación a los medios de no publicar la información oficial o la acusación a periodistas de venalidad o manipulación de parte de su medio, hasta represalias concretas como quita de publicidad oficial (Amado, 2011; ADC Acción por los derechos civiles, 2008). El Foro de Periodismo Argentino (Fopea), registra un crecimiento de 2008 a 2013 del 48\% de denuncias al monitoreo de atentados a la libertad de expresión (Informe 2013 del Monitoreo de Libertad de Expresión, 2014: web). De acuerdo a los casos registrados, las agresiones físicas o síquicas, las amenazas y el hostigamiento fueron los principales ataques. Las restricciones al acceso a la información son el 7\% del total de casos denunciados esos años y solo el año 2013 registró ocho casos en los que se impidió el acceso a conferencias. Una evidencia de la tensión que existe entre las fuentes oficiales y los periodistas es que los principales agresores denunciados son funcionarios públicos y fuerzas de seguridad, lo que muestra la paradoja de que los que deberían ser los garantes de la libertad de expresión son sus detractores.

En el caso de Argentina, el ejercicio del periodismo argentino debe contextualizarse en una comunicación presidencial que prescinde del periodismo como intermediario a partir de un potente sistema de propaganda y medios afines. Se trata de un sistema de flujo de comunicación top-down del actor político a los medios y a los ciudadanos (Mazzoleni, 2010: 33). Con los medios adopta la forma de news-management por el cual "el sistema de la política intenta condicionar (generalmente a su favor) la actividad de los medios", y con el actor ciudadano, combina una intensa comunicación institucional con propaganda y publicidad (Mazzoleni, 2010: 32). Estas circunstancias condicionan la orientación profesional de los medios hacia un periodismo sensible a las necesidades del sistema político (orientación sacerdotal) más que una lógica de trabajo que prioriza los valores periodísticos (orientación profesional pragmática) (Mazzoleni, 2010: 94). En el caso argentino, existe un importante conjunto de medios alineado políticamente y financieramente dependiente del Estado nacional, que replican la agenda oficial. Pero también aquellos que practican un periodismo adversario dependen de la información proporcionada por la oficina de prensa oficial para la cobertura de las noticias que involucran al Ejecutivo, con lo que siguen la agenda de eventos planificados y utilizan las imágenes y declaraciones distribuidas por la Secretaría de Comunicación Pública.

Las fuentes informativas diseñan los mensajes estratégicamente, presentándolos en los formatos y en los horarios más propicios para su difusión, con criterio de mercadotecnia para atraer la atención de los medios y por esa vía, la de sus audiencias (Martínez-Nicolás y Humanes, 2012: 50). Estas tácticas del news-management son propias de la información en contextos electorales pero se observan en periodos entre 
elecciones en gobiernos que eligen una estrategia de campaña permanente (Ornstein y Mann, 2000) en la que la comunicación de gobierno orientada a los ciudadanos se reemplaza por propaganda usada como instrumento de legitimación del partido gobernante en los periodos entre elecciones. Los objetivos del news-management "son los mismos en todos los contextos: los políticos presionan a los medios para obtener visibilidad, buena imagen y publicidad barata, al mismo tiempo que mantienen la distancia para proteger su mensaje y evitar ataques peligrosos" (Mazzoleni, 2010: 190). Esta estrategia usa técnicas como gestionar la información con los medios a través de spin-doctors; formular declaraciones en los momentos adecuados para la confección de noticias; asegurar el flujo de materiales pre-confeccionados; organizar temas y anuncios que los medios no tengan más remedio que cubrir; lanzar ataques exagerados contra los adversarios para llamar la atención de los medios. El sistema de gestión de prensa del gobierno argentino ha desarrollado estas tácticas con una impronta propia (Amadeo et al., 2013; Amado, 2010; Waisbord, 2013b):

- Desarrollo de varias agencias informativas dedicadas a la difusión de mensajes del gobierno ${ }^{2}$ y consolidación de las áreas de prensa oficiales como espacios de producción y control de lo publicado en los medios.

- Restricción de acceso de los medios a los actos oficiales, que son cubiertos por la oficina de prensa y los medios estatales. Las limitaciones alcanzan incluso a los periodistas acreditados en Casa de Gobierno que recién a fines de 2013 pudieron acceder a conferencias periódicas del Jefe de Gabinete de Ministros, pero no aun con la Presidente.

- Uso frecuente de la cadena nacional para transmitir en todas las señales de radio y televisión los anuncios presidenciales en horario central, coordinado con el cierre de los diarios y los noticieros de la noche. Durante su gobierno, Cristina Kirchner emitió un promedio de 154 discursos y 20 cadenas nacionales al año ${ }^{3}$.

- Alta productividad de gacetillas y material audiovisual de difusión. En la sala de prensa virtual se publican una media de 30 comunicados al día, con picos de

2 Los principales portales de difusión de información oficial son los siguientes: Secretaría de Comunicación Pública en

http://www.medios.gov.ar; Sitio de las actividades presidenciales, en

http://www.presidencia.gob.ar/_ Portal público de noticias del Estado Argentino, en http://www.argentina.ar; Sitio Oficial Guía del Estado, Presidencia de la Nación, http://www.argentina.gob.ar/; Sala de prensa, en http://www.prensa.ar; Agencia estatal de noticias, en http://www.telam.com.ar; Portal oficial de Cristina Fernández de Kirchner, http://www.cfkargentina.com/i. Presidencia para Chicos, en http://www.chicos.gov.ar/; Presidencia para No tan Chicos, en: http://www.notanchicos.gov.ar; Canal de You Tube de la Casa de gobierno, en: https://www.youtube.com/user/casarosada; Canal de You Tube Argentina en noticias, en: https://www.youtube.com/user/argentinaennoticias; Canal audiovisual de Telam, en: https://www.youtube.com/user/AudiovisualTelam [consultados en mayo de 2014].

3 Conteo de los discursos presidenciales publicados en el portal de la Casa de Gobierno, en http://www.casarosada.gov.ar/discursos, entre 2008 y 2012 [consultado en diciembre de 2013]. 
50 (Amado 2010: 84). A esto deben sumarse notas de opinión de los ministros, reportajes con temas del día, imágenes, audios y videos de los funcionarios. Dado que la mayoría de los ministros no hablan con la prensa, ese material se convierte en la única fuente de sus declaraciones.

- Limitaciones en el acceso a la información oficial, como cierre de páginas de consulta en línea, falta de respuesta de los funcionarios, selectividad de los medios con los que se mantienen relaciones informativas, voceros no autorizados a hacer declaraciones. A ello se suma la falta de actualización de las páginas con datos públicos ${ }^{4}$.

A la gestión estratégica de la información se agregan presiones directas para la reproducción de ese material en los medios y recriminaciones públicas si la cobertura no es del agrado del gobernante. La Asociación de Editores de Prensa de Argentina (ADEPA) emitió cincuenta comunicados referidos a la descalificación de la labor periodística desde 2004, año en que empezaron a expresar su rechazo a las invectivas y acusaciones hacia periodistas de autoridades ejecutivas y ministros de la Nación, que llegaron en no pocos casos a insultos y cargos criminales 5 . Aunque muchos marcan un inicio de las tensiones en 2008, en el gobierno de Fernández de Kirchner, los comunicados de la entidad empresaria confirman que "entre gran parte del periodismo y el gobierno había una guerra de baja intensidad desde la misma llegada de [Néstor] Kirchner en mayo de 2003. Desde un primer momento, el nuevo presidente interpretó que la gobernabilidad debía defenderse devolviendo con dureza las críticas periodísticas que recibía" (Ruiz, 2014: 398)

A la difusión de las actividades oficiales colabora todo un sistema de medios financiados principalmente por el Estado a la difusión de conformados por diecisiete grupos privados más el multimedios del Estado conformado por siete medios. Son los principales beneficiarios de la pauta oficial aunque no lograron consolidar audiencias $^{6}$. La contracara del estímulo financiero de medios afines son las como represalia a las coberturas críticas, como la persecución impositiva, la arbitraria asignación de licencias o la exclusión de la millonaria pauta oficial (Amado, 2011: 60). El caso em-

${ }^{4}$ Un ejemplo concreto de la falta de actualización de información esencial es el Gasto público consolidado: la última serie es de 2009 y está publicada en una página cuya última actualización fue en marzo de 2011. "Series de Gasto Público Consolidado por finalidad-función 1980-2009", Portal del Ministerio, en: http://www.mecon.gov.ar/pecono$\mathrm{mica} /$ basehome/serie_gasto.html [consultado en mayo de 2014]

5 Según surge de los informes de la Comisión de Libertad de Prensa e Información presentados en las Asambleas Anuales ADEPA (2003 a 2013), la asociación emitió declaraciones con quejas por agravios e insultos públicos de funcionarios nacionales y gobernadores. Los comunicados que se ocuparon específicamente de este tema fueron 4 en 2004; 3 en 2005; 4 en 2006; 3 en 2007; 3 comunicados y 5 solicitadas en 2008; 2 comunicados en 2009 y mención en 3 informes mensuales; 5 comunicados en 2010 y 2 solicitadas; 4 comunicados en 2011; 2 en 2012; 8 en 2013; 2 hasta febrero de 2014.

6 Alejandro Alfie: "Una gran red de medios alineados", diario Clarín, edición 9 de diciembre de 2012, en http://www.clarin.com/politica/gran-red-medios-alineados_0_825517515.html 
blemático es el de la editorial Perfil, editora de las revistas de mayor circulación que no recibe publicidad del ejecutivo desde 2003 y, a pesar de que cuenta con un fallo favorable de la Corte Suprema de Justicia de marzo de 2011, nunca logró que se subsanara la inequidad ni que sus periodistas fueran atendidos por los funcionarios.

El uso del material de las oficinas de prensa puede explicarse por razones de poder pero también por la provisión de información adecuada a las necesidades de los periodistas derivada de las urgencias de los tiempos o la escasez de recursos de los periodistas. La disponibilidad de material listo para ser publicado, con declaraciones de las autoridades nacionales, resulta muy conveniente para redacciones de bajos presupuestos y necesidad de ofrecer contenidos las veinticuatros horas. En Argentina, la tevé por cable sumó en los últimos años tres señales de noticias nacionales a las tres existentes a las que se suman nuevos canales temáticos. El proceso se potenció por el lanzamiento de la TV digital en 2009 y con la redistribución de frecuencias de radio que determinó la ley de Servicios de Comunicación Audiovisual promovida en el mismo año. Si bien la ley establecía una cuota de un tercio de frecuencia a la sociedad civil, lo cierto es que la mayor cantidad de señales se asignaron sin concursos a operadores estatales o a grupos económicos afines al gobierno ${ }^{7}$. Aunque se trata de medios con financiamiento mayoritario, si no exclusivo del Estado, lo más crítico para explicar la influencia de las fuentes oficiales es que se trata en su mayoría de medios de bajo presupuesto que se alimentan de la información producida por las oficinas de prensa y de pauta de las administraciones nacionales y locales que contratan espacios en esas señales para programas de producción gubernamental (Amado, 2010: 71).

Estas circunstancias impactan en el trabajo del reportero, en la medida en que "el periodista ya no oficia como un recolector activo de las informaciones, sino que ejerce una función de intermediario, publicando, procesándolo o no, el material disponible" (Kunczik, 2002: 282). Un contexto de alta productividad de las fuentes pero de información de baja calidad periodística impacta directamente en la forma en que se ejerce el periodismo, especialmente en el modelo de control (watchdog) que requiere facilidades para el escrutinio del poder (Mellado, 2014). En el contexto sudamericano la falta de marcos legales que garanticen el acceso a la información y la decisión de los gobiernos de obstaculizar la labor del periodista dificultan la producción de noticias sin la colaboración de las fuentes (Waisbord, 2000, 2013b). En estas condiciones es difícil para el periodismo alcanzar estándares de calidad en cuanto a la pluralidad de fuentes, uso de bases documentales primarias, porcentaje de temas propios, porcentaje de periodismo de investigación y libertad de la redacción en sus cometidos (Pablos Coello y Mateos Martín, 2004). Por otra parte, los bajos salarios y la falta de recursos exponen al periodista a conflictos de intereses, como verse obligado a aceptar contribuciones de la fuente como viáticos o recursos para realizar una cobertura.

7 En sus tres primeros años el organismo de aplicación autorizó 1256 radios, canales de TV y cable, $94 \%$ de los cuales pertenecen a entes gubernamentales. José Crettaz, "El 94\% de los medios creados con la nueva ley es estatal", diario La Nación, 2 de mayo de 2013, en http://www.lanacion.com.ar/1578091-el-94-de-los-medios-creados-con-la-nueva-ley-es-estatal 
La falta de intervención de los periodistas en la producción de ese material los convierte en copistas o en cultores de ese "periodismo de declaraciones" (Casero-Ripollés, 2012: 23) que se dedica a glosar lo que difunden las fuentes oficiales, que son las que marcan los ritmos de la agenda y el encuadre que se le da a los sucesos (Livingston y Bennett, 2003). En Argentina se convoca a los medios a transmitir los anuncios oficiales sin permitir la intervención de los periodistas, aunque es más frecuente que estos se realicen sin presencia de prensa. En la mayoría de los casos, los periodistas replican la información sin dar cuenta de las restricciones en que se obtuvo o aceptando el encuadre de conferencia de prensa que da el funcionario al evento, aunque no se hayan permitido las preguntas. De esta manera, los reporteros contribuyen a la estrategia oficial que busca mostrar una disponibilidad a la prensa que no es tal ${ }^{8}$.

Esta contradicción se puso en evidencia en los encuentros que la presidente mantuvo en setiembre de 2012 en las universidades de Harvard y Georgetown, en una gira por Estados Unidos. Varios estudiantes preguntaron acerca de por qué la mandataria no respondía preguntas a la prensa de su país, lo que permitió que la presidente hiciera explícita su estrategia de comunicación:

Yo hablo con millones de argentinos en los veinte mil actos donde voy. Hablo con periodistas en Formosa, en Córdoba, adonde me encuentran. ¿A vos te parece que si no hubiera hablado habría ganado con el $54 \%$ ? ¿A vos te parece que hubieran votado a una muda? ${ }^{9}$

En realidad hablar, hablo todos los días. Con la prensa hablo muchísimo. Cuando voy a actos, me entrevistan. Lo que sucede es que en la Argentina no hablar con la prensa es no decir lo que ellos quieren escuchar; me parece que hay una gran diferencia. Cualquiera que vaya a alguno de los actos políticos a los cuales voy en el [distrito conurbano] Gran Buenos Aires o en el interior del país... No hablo siempre, es cierto, no hablo todos los días. Pero si el periodista me pregunta, le respondo ${ }^{10}$.

En el estilo coloquial que la caracteriza, la presidente contestó sin disimular su incomodidad por la pregunta acerca del tiempo prolongado que llevaba sin hablar con el periodismo: "Es mentira eso de 'hace años'. He hablado muchísimo con periodistas acreditados en la Casa de Gobierno permanentemente". Aunque luego reconoció que no lo hace a través de conferencias de prensa regulares, la declaración motivó un comunicado de los periodistas acreditados en la Casa de Gobierno, en el que desmentían que tuvieran acceso a la funcionaria ${ }^{11}$. La ocasión también puso en evidencia

${ }^{8}$ En el portal oficial se mencionan algunos encuentros con la prensa, que justamente por el hecho mismo de que sean una noticia confirman su excepcionalidad (http://www.argentina.ar/temas/cristina/2668-cristina-saludo-a-los-periodistas-acreditados-en-casa-rosada).

9 "Cristina dio una conferencia en Harvard que fue tensa por momentos", diario El Litoral, 28 de setiembre de 2012, http://www.ellitoral.com/index.php/id_um/80960-cristina-dio-unaconferencia-en-harvard-que-fue-tensa-por-momentos

${ }^{10}$ Francisco Peregil, "Fernández responde en EE. UU. más preguntas que en un año en Argentina", diario El País, 28 de setiembre de 2012, en: http://internacional.elpais.com/internacional/2012/09/28/actualidad/1348792851_571040.html

11 "Los acreditados en Casa Rosada desmienten a la Presidenta", en diario La Nación, 26 de setiembre de 2012, en: http://www.lanacion.com.ar/1511902-los-acreditados-en-casa-rosadadesmienten-a-la-presidenta. 
ante la prensa internacional la táctica de los Kirchner de desautorizar la legitimidad del periodismo en base a acusaciones de supuestas actitudes hostiles de la prensa. En la descalificación se justifica la decisión oficial de no interactuar con los periodistas, aunque las afirmaciones sean generalmente exageraciones retóricas y carezcan de correlato fáctico, como las que vertió en esa ocasión:

Me gustaría que asistieras a alguna conferencia de prensa en la República Argentina, donde cuando a algún periodista no le gusta algo empieza a gritar y hacer escándalo y cosas que, realmente... [Sic] No todos, pero le ha tocado a algún ministro, por ejemplo, ser respondido [sic] en la sala de conferencias de la Casa Rosada. Y lo veo a Obama cuando da conferencias, el periodista pregunta, el presidente responde y allí termina. Allá, si no les gusta la respuesta que vos das, gritan, se enojan, patean una puerta... Una vez nos patearon una puerta en la Casa de Gobierno en la sala porque no les gustaba la respuesta que habían dado ${ }^{12}$.

En este contexto, se comprende que dos tercios de la ciudadanía definan como negativa la relación entre el periodismo y el gobierno (CIO Argentina, 2012: 90). Las encuestas sobre clima periodístico desarrolladas por el Foro de Periodismo Argentino en 2005,2011 y 2014 muestran el deterioro de la relacióndel gobierno con la prensa ${ }^{13}$. Los periodistas argentinos en 2011 evaluaron esa relación como mala o muy mala (55\%) o regular (29\%) y en 2014 calificaban con un 2.8 en una escala de 10 el vínculo con el gobierno nacional. En 2011, el 38\% de los periodistas afirmó haber recibido o saber que algún compañero de trabajo recibió llamadas o acciones coercitivas de funcionarios del Ejecutivo o de otros poderes del Estado (46\%). Señalan que solo en el 35\% de los casos se siguió adelante con la publicación de la nota prevista. En 2005, los encuestados calificaron al ejercicio del periodismo en Argentina como "Condicionado" (55,7\% de las respuestas) y "Complaciente" (segunda respuesta con 27,3\%). En la edición de 2011, un 58\% lo calificó de "Condicionado", un 12\% dice que es "Complaciente" y solo un $9 \%$ lo define como crítico, y el 2\% como independiente. En la de 2014 , las respuestas se mantuvieron con leves modificaciones, como que "Condicionado" aumentó a $61 \%$ y bajó a $1 \%$ los que lo calificaron como "Independiente". En 2011, el 48\% de los periodistas señaló la influencia del departamento comercial en la sala de redacción, con impacto mayor de la pauta oficial (38\% de las respuestas) que de la anunciantes privados (12\%). En 2014, la influencia del departamento comercial aumentó a $60 \%$, la publicidad oficial era señalada como el segundo problema que enfrentaba la profesión (37\%) con el mismo porcentaje que la falta de rigor periodístico, ambos factores que se relacionan con el primer problema identificado, que es el nivel salarial (48\%). En la edición de 2014 se indagó especialmente sobre las cuestiones de

${ }^{12}$ Peregil, Op. Cit.

${ }^{13}$ Foro de Periodismo Argentino y Giacobbe y Asoc. (2005), "Sobre los periodistas y su profesión", (p. 25), Buenos Aires, en http://www.fopea.org/Etica/Encuesta_sobre Periodismo; Foro de Periodismo Argentino y CIO Argentina (2011), "Encuesta sobre los periodistas y su profesión", Buenos Aires, en: http://www.www.fopea.org/Recursos/Biblioteca Virtual/Estudios/Clima_de_la_Actividad_Periodistica_de_la_Argentina; Foro de Periodismo Argentino y CIO Argentina (2014), "Clima de la actividad periodística en Argentina" (p. 63), Buenos Aires, en http://www.fopea.org/Inicio/Encuesta_sobre_la_autocensura_en_el_periodismo_argentino 
autocensura, en la que los periodistas reconocieron que existe en un alto porcentaje en su medio (51\%) pero que conoce más casos en otros medios (91\%). Cuando se precisó sobre qué temas operaba más la autocensura la primera respuesta fue las cuestiones vinculadas con el gobierno nacional (48\%), seguido por la trata de personas (31\%) y narcotráfico (30\%), también bajo su responsabilidad ${ }^{14}$.

Esto configura formas indirectas de presión al periodismo, más sutiles que las de antaño, pero que se hicieron corrientes en las democracias latinoamericanas del siglo XXI: "Pese a que no se basan en métodos violentos o en una censura formal, los gobiernos electos pueden disuadir/desalentar un periodismo de ataques muy duros. Desde obstaculizar el acceso a la información oficial hasta ofrecer recompensas materiales a medios o periodistas aduladores, los gobiernos controlan diversos mecanismos para mantener a la prensa con riendas cortas" (Waisbord, 2013b:151).

La independencia periodística es contingente al contexto económico y político y la profesionalización es una estrategia para establecer los límites a estas condiciones (Waisbord, 2013a: 69). Si hay consenso entre los periodistas acerca de reglas básicas de las prácticas profesionales y pueden reafirmar colectivamente autoridad y credibilidad, es más probable que la profesión pueda mantener su autonomía (Waisbord, 2013a: 70). A la inversa, la falta de acuerdo en cuestiones básicas tales como la posición a adoptar ante las restricciones impuestas por las fuentes de poder y la imposibilidad de organizarse colectivamente dan cuenta de esa debilidad institucional que aparece en la opinión de los periodistas sobre su rol profesional.

\section{Análisis: Periodistas sin preguntas}

Desde el inicio del periodo democrático en 1983, los presidentes argentinos mantuvieron contactos con la prensa, con voceros activos y conferencias de prensa regulares. A fines de 2001 Argentina atravesó una crisis política que resultó en la designación de un presidente provisional y una emergencia económica y social que habilitó situaciones de excepción en los distintos órdenes de funcionamiento institucional, de los cuales no escapó la prensa. Gobierno y medios entendieron que una forma de garantizar la estabilidad democrática era adoptar una política informativa prudente. El presidente de la transición Eduardo Duhalde (2001-2003) dio pocas conferencias lo que su vocero justificó en que la prioridad de la comunicación gubernamental fue brindar certeza de continuidad a la población (Lavalle y Schmidt, 2009: 42).

Cuando asume Néstor Kirchner (2003-2007), lo hizo con un débil apoyo del 23\% de los votos y una frágil alianza de apoyos políticos con lo que los medios desarrollaron un prudente "periodismo de seguridad democrática por tres razones: el fracaso de Kirchner pondría en riesgo la continuidad democrática, los medios estaban también débiles y dependientes de decisiones oficiales y había una afinidad ideológica de centroizquierda entre la mayoría de los periodistas y Kirchner" (Ruiz, 2014: 392). Este contexto inicial le permitió sentar las bases de un sistema que definió como de comunicación directa con la ciudadanía que cerró progresivamente los canales de inter-

${ }^{14}$ Ibid., 2014, pregunta “¿Cuáles considera que son los temas de interés público que no se publican, o se publican en forma insuficiente, por autocensura de los periodistas?", respuestas múltiples. 
cambio con los periodistas y consolidó un sistema de propaganda y medios oficiales. Su esposa y sucesora en el cargo en 2007 y reelecta en 2011, Cristina Fernández de Kirchner, consolidó el sistema con una inversión en propaganda y control de lo publicado cuya estructura insume desde 2008 alrededor de cien millones de euros al año, lo que de acuerdo al presupuesto nacional representa un crecimiento de más de tres mil por ciento desde 2003. A pesar de que su base electoral duplicó a la de su antecesor en las dos elecciones que ganó y que no existían amenazas de inestabilidad política o social, tomó la decisión de clausurar los espacios de acceso de la prensa y desarrollar un sistema de control de la información pública.

El presidente Néstor Kirchner mantenía una relación pragmática con los periodistas, que significó acceso selectivo a la información que manejaba estratégicamente con el diario de mayor circulación del país. Puede definirse como "una relación estable con directivos de Clarín y una más inestable con sus periodistas" (Ruiz, 2014: 399), en las que el presidente y su jefe de gabinete concedían selectivamente las entrevistas o manejaban con el diario la información a través de conversaciones off the record. Aunque su sucesora evitó el contacto con la prensa, ambos mandatarios coincidieron en utilizar los anuncios oficiales y los mensajes por cadena nacional para comunicar las novedades a la vez que formulaban críticas abiertas a la prensa en general y duras acusaciones a ciertos medios o periodistas en particular, con las que justificaban su decisión de prescindir de la intermediación de la prensa. La cercanía que Néstor Kirchner tuvo con Clarín se volvió en franca hostilidad hacia los medios del grupo que se convirtieron en blanco de las críticas a la prensa adversaria durante el gobierno de Cristina Fernández (2007-2011; 2011-2015). Los funcionarios solo aceptaban conferencias de prensa en el extranjero o con visitantes del exterior, o imponiendo restricciones de acceso. Por caso, el 2 de marzo de 2010 se excluyó a un periodista del diario Clarín de una conferencia del Ministerio de Trabajo alegando que "sus artículos eran muy agresivos". El mismo año ocurrió algo similar con otros periodistas del diario en ruedas de prensa de ese ministerio en Brasil y en Cancún. En otros casos, se realizaron señalamientos o acusaciones severas a periodistas que preguntaban, como hizo la presidente en la conferencia que dio el 3 de febrero de 2010. Esta fue la segunda conferencia, luego de la de agosto de 2008, y antes de la tercera que dio en agosto de 2011, en la que solo permitió cinco preguntas.

La principal reacción de las asociaciones de medios y de periodistas fue elaborar comunicados para dar a conocer las hostilidades y presentaciones ante organismos internacionales como la Sociedad Interamericana de Prensa. Desde la sociedad civil, hubo dos iniciativas para reivindicar los espacios comunes de producción de información pública. La primera fue la de un grupo de veinte periodistas que, con el apoyo de la Fundación Konrad Adenuaer, dio impulso al programa "Preguntar al poder" que intentaba generar espacios de reflexión sobre la información pública y propiciar conferencias de prensa en las que fueran los periodistas los que invitaban a los funcionarios a dialogar ${ }^{15}$. La idea era replicar la iniciativa de la Conferencia de Prensa Federal

${ }^{15}$ El proyecto fue ejecutado por el Centro para la Información Ciudadana, en http://www.infociudadana.org.ar/ [consultado en abril de 2014]. 
(Bundespressekonferenze), una asociación civil de los periodistas alemanes que funciona desde 1949 con el objetivo de solicitar a los funcionarios conferencias de prensa abiertas y regulares (Linnarz, 2004). El programa impulsó reuniones de discusión con periodistas y jefes de prensa que derivó en un ciclo de conferencias de prensa abiertas que se inició en 2007 con el presidente de la Corte Suprema de Justicia de la Nación como entrevistado. En los sucesivos encuentros tuvo la adhesión del Foro de Periodismo Argentino (Fopea), el Círculo de Periodistas Parlamentarios, los corresponsales extranjeros, de varios medios y agencias y la asociación empresaria ADEPA como así también el apoyo de universidades que fueron anfitrionas de las conferencias (Lavalle y Schmidt, 2009).

Durante los primeros tiempos se organizaron nueve conferencias al año con representantes de los tres poderes pero el número bajó a seis en 2010 y a tres en 2012, cuando se realizó la última de un total de $39^{16}$. En el programa participaron funcionarios de los tres poderes: trece del poder ejecutivo nacional y provincial; seis del legislativo; $y$ tres del judicial, así como directivos de sindicatos, organismos de control y medios, algunos de los cuales lo hicieron en dos oportunidades. Con el cambio de autoridades en el Congreso Nacional en 2011, presidido por el vicepresidente Amado Boudou, la colaboración que había prestado ese organismo en los años previos se suspendió, como así la posibilidad de realizar actividades con el Círculo de Periodistas Parlamentarios. En 2013 ninguno de los invitados habituales aceptó participar y no se obtuvo respuesta de las cartas enviadas regularmente por los organizadores a los ministros del Poder Ejecutivo. Pese a haber sido un año electoral y que en elecciones anteriores habían participado doce candidatos a distintos cargos, todos los invitados se excusaron. Para entonces, los periodistas del grupo promotor se habían alejado del proyecto y el programa en 2013 se dedicó a generar encuentros y talleres para discutir la problemática con periodistas, políticos y estudiantes de periodismo y relaciones públicas.

En 2012 varios periodistas agrupados bajo el nombre "Conferencias de prensa" publicaron siete comunicados en un sitio web ${ }^{17}$ sobre distintos temas relacionados con el ejercicio del periodismo. El primero fue una carta pública del 20 de marzo de 2012 dirigida al Jefe de Gabinete de Ministros, Juan Manuel Abal Medina, en respuesta a sus declaraciones que sostenían "a los comentaristas que dicen que no damos conferencias de prensa o que hablamos poco, les digo que no se preocupen. Si hablamos poco es porque estamos trabajando porque la política es eso: trabajar, esforzarse y gestionar todos los días para mejorar la vida de todos los argentinos"18. A ello, la carta

${ }^{16}$ Listado de entrevistados en el ciclo "Preguntar al poder", en: http:/www.infociudadana.org.ar /conferenciasdeprensa/entrevistados/nombres/ [consultado en abril de 2014].

${ }^{17}$ Comunicados del grupo "Conferencia de prensa", en http://conferenciadeprensa.tumblr.com/ [consultado en mayo de 2014].

${ }^{18}$ Declaraciones en el discurso inaugural del encuentro "Patria Grande Conectada", pronunciado el 19 de marzo de 2012, "Estamos construyendo un país con los 40 millones de argentinos adentro", cable de Agencia Telam, 19 de marzo de 2013, en http://www.telam.com.ar/notas/201203/13591-estamos-construyendo-un-pais-con-los-40millones-de-argentinos-adentro.html 
suscripta por 132 periodistas respondía que "frente a la imposibilidad de hacerlo en los escenarios habituales y para no abdicar de nuestro derecho a recabar información, quienes suscribimos este texto le informamos que, de aquí en adelante, haya o no contestación, formularemos las preguntas que consideremos de interés a través de los medios que estén a nuestro alcance" ${ }^{19}$. El último de los comunicados, del 4 de julio de 2013, era un repudio a los insultos del Secretario de Comercio Interior de la Nación, Guillermo Moreno, a periodistas del diario Clarín y fue suscripto por 197 periodistas.

En mayo de ese año muchos de estos periodistas participaron en un programa de televisión ${ }^{20}$ en el que se invitaba en las redes sociales a expresar las preguntas que le harían a los funcionarios con la consigna \#Queremospreguntar. Ese evento tuvo una importante cobertura en otros medios aunque el reclamo fue perdiendo fuerza con los días $^{21}$. En referencia a este planteo, hubo varias declaraciones de funcionarios para ratificar la decisión de no dar conferencias ${ }^{22}$. Gabriel Mariotto, vicegobernador de la provincia de Buenos Aires y ex director del organismo de control de los medios audiovisuales, opinó que "la Presidenta se comunica de su forma, son formatos, pero eso no afecta la comunicación. Puede comunicarse con su pueblo sin dar conferencias"23.

A pocos días del suceso la presidente tuvo un encuentro casual con los periodistas acreditados casa de gobierno, mientras recorría las refacciones que se estaban haciendo en el predio. Aprovechando lo excepcional de la situación los periodistas le reclamaron por la falta de información y la imposibilidad de acceso a la agenda oficial. La presidente contestó "Para información oficial están mis discursos. Yo no voy a hablar contra mí misma"24. Además justificó el ocultamiento de su agenda de trabajo diario porque, sostuvo, "la cambiamos todo el tiempo. Si la informamos después ustedes dicen que [la modificación] es por una [pelea] interna o cualquier cosa". En la ocasión expresó su satisfacción con los periodistas que trabajan en la sala de prensa presidencial que escribían "correctamente" sobre sus actividades, y se quejó con ironía de que esos comunicados luego eran tergiversados por los medios.

La única asociación de periodistas, Fopea, que nuclea unos trescientos socios, en 2008 dio cuenta en un comunicado de las actitudes del para entonces expresidente y

${ }^{19}$ Carta abierta a Señor Jefe de Gabinete de Ministros Juan Manuel Abal Medina, 28 de marzo de 2012, en http://conferenciadeprensa.tumblr.com/post/20092188661/senor-jefe-de-gabinete-de-ministros-juan-manuel [consultado en mayo de 2014].

${ }^{20}$ Programa "Periodismo para todos", conducido por Jorge Lanata, Canal 13, Buenos Aires, edición del domingo 13 de mayo de 2012.

21 "\#queremospreguntar, el reclamo de Lanata para la Presidenta", diario La Nación, 14 de mayo de 2012, en http://www.lanacion.com.ar/1473104-queremos-preguntar-el-reclamo-delanata-para-la-presidenta [consultado en 11/5/14]

${ }^{22}$ Asociación de Entidades Periodísticas Argentinas (ADEPA), Informe mayo de 2012.

23 "La polémica entrevista de Fantino a Mariotto incendió Twitter", diario La Gaceta, 16 de mayo de 2012, en http://www.lagaceta.com.ar/nota/491180/politica/polemica-entrevista-fantino-mariotto-incendio-twitter.html

${ }^{24}$ Juan Ignacio Irigaray "Cristina Kirchner: 'La información oficial son mis discursos. No hablo contra mí", diario $A B C$, edición 25 de mayo de 2012, en http://www.elmundo.es/america/2012/05/25/argentina/1337966152.html 
titular del Partido Justicialista: "En dos oportunidades, [Néstor] Kirchner se prestó a rondas de prensa en las que se permitió juzgar con sorna la intencionalidad de las preguntas que le fueron formuladas, lo que provocó risotadas de aprobación de los partidarios que lo rodeaban." ${ }^{25} \mathrm{La}$ asociación emitió varios comunicados reclamando conferencias de prensa ${ }^{26}$. En la conmemoración del día del periodismo, el 7 de junio de 2012, impulsó "una campaña en todo el país para proponer que se generen estos mecanismos profesionales de conferencias de prensa en todos los niveles del estado, con la posibilidad de realizar preguntas, y sin la presencia de simpatizantes o seguidores"27. Para las elecciones legislativas de 2013 la asociación de periodistas y veinticinco organizaciones impulsaron una campaña en la que cien candidatos suscribieron el compromiso de dar conferencias de prensa y asegurar la transparencia de sus actividades, petición que fue acompañada por mil adherentes ${ }^{28}$.

La tibia adhesión a ambas iniciativas y su incierta continuidad marcan una diferencia con la iniciativa española \#sinpreguntasnocobertura (Díaz Nosty, 2011: 49) cuyo manifiesto logró la adhesión de asociaciones profesionales y más de once mil profesionales $^{29}$. El símbolo gráfico que identifica que la nota fue producida sin preguntas fue adoptado por diversos medios de España cosa que no se logró en Argentina, donde incluso se mantiene la denominación de conferencia de prensa para los eventos que no admiten la participación del periodismo.

En comparación con el modelo alemán que sirvió de referencia para el programa "Preguntar al poder", los periodistas tuvieron parte activa para sostenerlo en el tiempo, a pesar de las turbulencias de los primeros momentos cuando la institución no era reconocida por el canciller alemán (Krüger, 2009: 68). Con los años pudo pasar del modelo de círculos de conversación inicial al formato abierto y la asociación pudo consolidarse como un espacio institucional reconocido por periodistas, jefes de prensa y funcionarios (Linnarz, 2004; Krüger, 2009). En cambio, en el caso argentino no se logró continuidad con el grupo promotor cuyos miembros se alejaron del proyecto por diversas razones, entre las cuales la principal fue el desgaste que generaba la negativa de los funcionarios principales. El año en que hubo más pedidos públicos de

${ }^{25}$ Fopea, "Modos inadmisibles para conferencias de prensa", comunicado de 11 de julio de 2008, en http://www.fopea.org/Inicio/Modos_inadmisibles_para_conferencias_de prensa

26 "Fopea vuelve a reclamar la realización de conferencias de prensa profesionales", comunicado de 27 de febrero de 2012, en: http://www.fopea.org/Inicio/Fopea_vuelve_a reclamar_la_realizacion_de_conferencias_de_prensa_profesionales [consultāo en màyo de $201 \overline{4}]$

${ }^{27}$ Fopea, "FOPEA aprovecha el día del periodista para debatir sobre el ejercicio profesional", en 7 de junio de 2012, en: http://www.fopea.org/Inicio/FOPEA_aprovecha_el_dia_del_periodista_para_debatir_sobre_el_ejercicio_profesional; "FOPEArreitera su reclamo por conferencias de prensa", 27 de setiembre de 2012, en http://www.fopea.org/Inicio/FOPEA reitera_su_reclamo_por_conferencias_de_prensa [consultado en mayo de 2014]

${ }_{28}$ Petición "Para mejorar la Calidad de la Información en Democracia - \#InfoenDemocracia", en http://www.change.org/es-AR/peticiones/para-mejorar-la-calidad-de-la-informaci $\% \mathrm{C} 3 \%$ B3n-en-democracia-infoendemocracia

${ }^{29} \mathrm{http}$ //www.peticionpublica.es/?pi=P2011N9499 [consultada en abril de 2014] 
conferencias fue el año en el que el programa "Preguntar al poder" pudo organizar la menor cantidad de encuentros, lo que evidenció que sus esfuerzos no estuvieron coordinados. El contraste de las actitudes asumidas por los periodistas europeos con los argentinos en esos casos la aceptación de las condiciones que establecen las fuentes oficiales hace patente las diferentes culturas profesionales.

\section{Discusión: Periodismo sin calidad}

El cambio del Jefe de Gabinete de ministros en diciembre de 2013 pareció revertir la situación dado que se comprometió a brindar una conferencia de prensa diaria, aunque permite muy pocas preguntas, cuando no se limita a hacer anuncios. Como ocurre con la información oficial, sus declaraciones se replican en todos los medios, muchos de los cuales las transmiten en directo. La cobertura se centra en comentarios a esas declaraciones o pedidos de opiniones de especialistas $u$ otros funcionarios, en un estilo más propio al periodismo de comentarios que al reportero que toma la iniciativa en la búsqueda de la información. Como muestra una investigación española, la acción de las oficinas de prensa que promueven las conferencias sin preguntas actúa como un mecanismo de control del periodismo, potenciado por la potestad del gobierno nacional en la asignación de licencias y publicidad oficial (Humanes et al., 2013: 728). Este modelo pautado por la iniciativa de las oficinas de prensa hace que aún el periodismo crítico se encuadre en la agenda de temas pautada por el poder y produzca noticias con predominio de las fuentes oficiales (Clayman et al., 2007; Sigal, 1973; Davis, 2009).

Esto marca una diferencia con relación a la iniciativa alemana que desde el inicio entendió que "el derecho de pregunta-ilimitado temática y temporalmente- asegura que la Bundespresskonferenz no sea un foro de difusión del gobierno federal" (Linnarz, 2004: 58). Ese modelo entiende que es el ejercicio de la pregunta lo que otorga credibilidad a la información pública. De hecho, la negativa a dar conferencias de prensa es el punto de la comunicación del gobierno argentino más rechazado por la ciudadanía (57\% en desacuerdo) seguido por el uso de propaganda y de la cadena nacional ${ }^{30}$. La decisión de utilizar canales institucionales ha sido justificada por los presidentes Kirchner en que el periodismo no reporta adecuadamente sus novedades. La presidente los acusó reiteradamente de enfocarse demasiado en la crítica y el cuestionamiento, justamente aquellas actitudes que definen el modelo de periodismo de control (Mellado, 2014). En uno de sus discursos denominó a los medios críticos como "La cadena del odio y del desánimo", haciendo un juego de palabra con las en respuesta a los señalamientos de la prensa por el uso abusivo de la cadena nacional para comunicar novedades presidenciales. En el sitio oficial de Cristina Fernández de Kirchner existe una sección llamada "La cadena del desánimo"31 donde se publican los señalamientos a la prensa que la mandataria hace en sus discursos o en su cuenta de Twitter.

\footnotetext{
${ }^{30}$ CIO Argentina (2012). Ibid.

31 "La cadena del desánimo" tiene 17 comunicados desde 16 de febrero de 2013, en http://www.cfkargentina.com/category/cfk/la-cadena-del-desanimo/[consultado en mayo de 2014]
} 
Su queja recurrente puede resumirse en lo que señala como "Contradicciones permanentes [del periodismo]: que si [la presidente] habla, que si no habla, que cuando habla no la publican $[\mathrm{sic}]^{\prime 32}$. En este sentido, su actitud la encuadra en el grupo de presidentes esquivos a la prensa, como Richard Nixon y como él, además de evitar a los periodistas emprendió una campaña de descalificación con el vicepresidente Agnew $\mathrm{y}$ un redactor de discursos, donde acusaba a los periodistas norteamericanos de tergiversar la información y de dar a la información un "sesgo liberal" (Clayman y Heritage, 2002: 10).

La investigación de Clayman y Heritage sobre la entrevista presidencial concluye que esa instancia es un componente central en la esfera pública contemporánea, potenciada por las facilidades técnicas para la producción de noticias y el aumento de espacios noticiosos. Es el espacio donde los periodistas desempeñan su papel democrático más claramente: dialogan a la vista del público con funcionarios de los más altos rangos y les piden rendición de cuentas dentro de los parámetros del debate público (Clayman y Heritage, 2002: 2). Agregan que aquellos políticos que saben desenvolverse frente a preguntas difíciles, como John Kennedy y Margaret Thatcher, son más respetados que aquellos que son criticados por su mal desempeño ante la prensa, como Ronald Reagan (Clayman y Heritage, 2002: 3). Fundamentalmente porque al ser impredecible aun con una agenda preestablecida, la conferencia es el espacio de mayor credibilidad. Sin embargo, es este aspecto el que se resigna cuando se reemplaza la interacción directa del periodista con el funcionario por material producido por la fuente. La gran cantidad de discursos presidenciales transmitidos en directo y publicados apenas se terminan está más cerca de la propaganda que de la comunicación pública que permite la interacción del funcionario con el periodista. Silvio Waisbord en su análisis del estilo de comunicación de los gobiernos populistas concluye que el anuncio de supuestos logros de un gobierno "no está vinculado con la lógica del conocimiento público. Es propaganda, no comunicación. Se trata de información dominada por el interés oficial de cortejar la opinión pública con verdades parciales más que el interés de fomentar deliberaciones sobre actos de gobierno" (Waisbord, 2013b: 73).

Si bien la prensa ya no es la única fuente informativa porque numerosas instituciones producen abundante información sobre sí mismas, ninguna tiene la función exclusiva de producir y distribuir información regularmente como lo hace el periodismo (Waisbord, 2013a: 139). El gobierno argentino abiertamente se ha propuesto convertirse en una institución productora de información alternativa al periodismo, y cuenta con medios propios o alineados que le sirven de canales de distribución alternativos a la prensa tradicional, con presupuestos superiores a los de cualquier medio. De hecho en Argentina el presupuesto asignado a la prensa y la propaganda presidencial es varias veces superior al asignado a los medios públicos. Por su posición de poder, se propone incluso como más legítima productora de información pública en la medida en que, según sus términos, los periodistas responden a intereses espurios, sea porque

32 "El 'prolongado silencio de Cristina Kirchner", publicado en el sitio oficial de Cristina Fernández de Kirchner, 30 de enero de 2014, http://www.cfkargentina.com/el-prolongado-silencio-de-cristina-kirchner/ [consultado en mayo de 2014] 
anteponen los intereses comerciales de sus patrones, sea porque responden a poderes fácticos enemigos de la democracia. En esta razón de supuesta defensa de la democracia de la cual el gobierno se postula como único garante es que legitima una comunicación que define como directa con la ciudadanía, omitiendo la intermediación periodística.

La omisión de conferencias de prensa encuadra en esta estrategia en la medida en que los funcionarios muestran a la ciudadanía que pueden prescindir de los periodistas para informar a la ciudadanía. La estrategia del gobierno argentino se inscribe en la comunicación de los gobiernos populistas que consiste en evitar la participación de medios enfrentados al Gobierno y negar la posibilidad de que el periodismo formule preguntas para "minimizar o debilitar la mediación periodística que pueda colocar preguntas incómodas o introducir temas fuera del interés oficial" (Waisbord, 2013b: 168). De esta manera, "los actores políticos pretenden tutelar los significados que se transmiten de sus actividades y la imagen que de ellos se difunde a través de la pantalla. Sus energías se concentran en hacer que el contenido de sus mensajes llegue íntegramente, sin sufrir alteraciones, al público" (Casero-Ripollés, 2009: web). Sin embargo, la falta de un interlocutor que pueda hacer preguntas evidencia la falacia de la supuesta comunicación directa, dado que solo circulan mensajes desde la perspectiva oficial, sin que la ciudadanía tenga esa misma potestad de interrogar o cuestionar los mensajes que recibe.

El periodismo se define por ser productor de noticias, que se distinguen de la información institucional que producen las administraciones públicas, empresas y organizaciones civiles (Waisbord, 2013a: 142). Cuando resigna esa exclusividad, que es lo que lo define como un campo profesional, pierde identidad como profesión. Pero a la vez, al adoptar la perspectiva oficial o aceptar el temario propuesto por el gobierno, la prensa corre el riesgo de ser vista como "la 'custodia de la voz oficial' con lo que renunciaría al mandato tradicional de ser portavoz independiente de la voz del pueblo" (Bennett, 1990: 106). De esta manera, el gobierno se propone como la única voz autorizada para hablar de lo público que a su vez él mismo define:

En una irónica reformulación del ideal democrático, la opinión pública moderna podría definirse como el resultado de la 'indexación' de las voces institucionales dominantes en los medios. Al adoptar esa opinión indexada, los medios contribuyen a crear un universo político que proviene, culturalmente hablando, de arriba hacia abajo. Es decir, un mundo donde el gobierno define sus públicos y 'democracia' resulta ser lo el gobierno haga (Bennett, 1990: 125).

La debilidad de las iniciativas de los periodistas argentinos para compensar la falencia da cuenta de la frágil identidad profesional y la escasa capacidad asociativa, que se remite a una tensión histórica entre gobierno y medios. Las tácticas de los Kirchner se parecen mucho a lo que hizo el presidente Hipólito Yrigoyen en la década de 1930, de subvención de diarios dispuestos a brindar una cobertura oficialista, no dar entrevistas ni tener contacto con los corresponsales de la casa de gobierno y supervisar personalmente el contenido que publicaba el diario oficial (Ruiz, 2014: 182). A su vez, el intenso uso de la propaganda y la construcción de un sistema de medios alineados al gobierno tiene su antecedente en el gobierno de Juan Domingo Perón, a me- 
diados del siglo pasado (Mercado, 2013). El sistema atenta directamente contra un trabajo de calidad por cuanto si el editor depende de la información oficial, "es posible que verifique menos la información que le traen los periodistas si esta es políticamente fuerte, y entonces el medio se devalúa profesionalmente mientras se carga políticamente. Se gana en contundencia política y se pierde en calidad informativa" (Ruiz, 2014: 412).

La continuidad en el tiempo del sistema determina una naturalización de las condiciones a las que se terminan acomodando los medios en la medida en que es más barato difundir y comentar la información que producen las fuentes oficiales que promover investigación independiente. Con lo que el sistema se ratifica a sí mismo. El hecho de que crezcan las agresiones a los periodistas y aumenten las dificultades para desarrollar información independiente de la decisión de la fuente da cuenta de las condiciones en que se ejerce el periodismo en Argentina. La pérdida de las conferencias de prensa no solo menoscaba la transparencia en que el periodista interroga al poder sino que desvaloriza los espacios colectivos de producción de información a favor de un sistema de competencia por la noticia exclusiva o las filtraciones. En todos los casos, el periodista se convierte en un personaje dependiente de la decisión del poder o del político que concede como dádiva o bien de cambio la información que no se puede obtener por vías equitativas y transparentes.

\section{Referencias bibliográficas}

ADC Acción por los derechos civiles (2008): Abuso de publicidad oficial y otras formas. Buenos Aires, ADC.

ADC Acción por los derechos civiles (2013): Un derecho débil: investigación sobre el derecho de acceso a la información pública en la Argentina. Buenos Aires, ADC.

AMADEO, Belén; AMADO, Adriana; ARUGUETE, Natalia (2013): "La comunicación K o el relato del modelo. Argentina 2005-2011", en RINCÓN, Omary; PONCE, Matías (eds.): Caudillismo, e-política y teledemocracia: Comunicación de gobierno en América Latina. Montevideo, Fin de siglo, Fundación F. Ebert, pp. 19-38.

AMADO, Adriana (2010): La palabra empeñada. Investigaciones sobre medios y comunicación pública en Argentina. Buenos Aires, Centro de Competencia en Comunicación, Fundación F. Ebert.

AMADO, Adriana (2011): "Las prensas de la prensa: poder y periodismo en la Argentina del 2009", en RETTBERG, Angélika; RINCÓN, Omar (eds.): Medios, democracia y poder. Bogotá, Editorial Uniandes, pp. 53-78.

BENNETT, Lance (1990): “Toward a Theory of Press-State Relations in the United States". Journal of Communication, 40 (2), pp. 103-127.

BLUMLER, Jay; KAVANAGH, Dennis (1999): "The Third Age of Political Communication: Influences and Features". Political Communication, 16 (3), pp. 209230 . 
CASERO-RIPOLLÉS, Andreu (2009): "El control político de la información periodística". Revista Latina de Comunicación Social, 64, en: http://www.revistalatinacs.org/09/art/29_828_47_ULEPICC_08/Andreu_Casero.html

CASERO-RIPOLLÉS, Andreu (2012): "El periodismo político en España: algunas características definitorias", en Periodismo político en España: concepciones, tensiones y elecciones. Tenerife, Sociedad Latina de Comunicación social, pp. 19-46.

CLAYMAN, Steven; ELLIOTT, Marc; MCDONALD, Laurie (2007): "When Does the Watchdog Bark? Presidential News Conferences". American Sociological Review, 72, pp. 23-41.

CLAYMAN, Steven; HERITAGE, John (2002): The News Interview: Journalists and Public Figures on the Air, Canadian Journal of Communication. Cambridge, Cambridge University Press.

CYTRYNBLUM, Alicia (2008): Niñez y adolescencia en la prensa argentina. Buenos Aires, Periodismo social.

CYTRYNBLUM, Alicia (2009): El encierro mediático. Buenos Aires, Periodismo Social.

DAVIS, Aeron (2009): "Journalist-Source Relations, Mediated Reflexivity and the Politics of Politics”. Journalism Studies, 10 (2), pp. 204-219.

DE LA TORRE, Lidia; TÉRAMO, María Teresa (2004): La noticia en el espejo. Medición de la calidad periodística: la información y su público. Buenos Aires, Editorial de la Universidad Católica Argentina.

DE LA TORRE, Lidia; TÉRAMO, María Teresa (2007): "Investigación sobre calidad periodística argentina", en AMADO, Adriana (ed.): Periodismo de calidad: debates y desafios. Buenos Aires, Fopea, La Crujía, pp. 39-62.

DÍAZ NOSTY, Bernardo (2011): El libro negro del periodismo en España. Madrid, Asociación de la Prensa de Madrid.

FERNÁNDEZ PEDEMONTE, Damián (2010): Conmoción pública. Buenos Aires, La Crujía.

GANS, Herbert (1979): Deciding What's news. A Study of CBS Evenings news, NBC Nightly, Newsweek and Time, 2004. New York, Northwestern University Press.

HUMANES, María Luisa; MARTÍNEZ-NICOLÁS, Manuel; SAPERAS, Enric (2013): "Political Journalism in Spain. Practices, Roles and Attitudes". Estudios sobre el Mensaje Periodístico, 19 (2), pp. 715-731. Madrid, Servicio de Publicaciones de la Universidad Complutense.

KRÜGER, Gunnar (2009): Bundespressekonferenz: los origenes del modelo alemán de conferencia de prensa federal. Buenos Aires, Konrad Adenauer Stiftung.

KUNCZIK, Michael (2002): Conceitos de jornalismo. São Paulo, Editora da Universidade de São Paulo.

LAVALLE, Dolores; SCHMIDT, Cornelia (2009): Las conferencias de prensa en la Argentina. Buenos Aires, Fundación Konrad Adenauer. 
LINNARZ, Paul (2004): "Libertad de prensa vivida. El modelo de Bundespressekonferenz e.V. de Alemania como oportunidad para América Latina". Derecho comparado de la información, I (4), pp. 49-77.

LIVINGSTON, Steven; BENNETT, Lance (2003): "Gatekeeping, Indexing, and LiveEvent News: Is Technology Altering the Construction of News?". Political Communication, 20 (4), pp. 363-380.

MARTÍNEZ-NICOLÁS, Manuel, HUMANES, María Luisa (2012): "Culturas profesionales del periodismo político en España. El discurso de los periodistas sobre la política y las funciones políticas de los medios", en CASERO-RIPOLLÉS, Andreu (Ed.): Periodismo político en España: concepciones, tensiones y elecciones, Tenerife, Sociedad Latina de Comunicación social, pp. 47-65.

MAZZOLENI, Gianpietro (2010): La comunicación política. Barcelona, Alianza Editorial.

MELLADO, Claudia (2014): "Professional roles in news contents: Six dimensions of journalistic role performance". Journalism Studies. DOI 10.1080/1461670X .2014 .922276

MERCADO, Silvia (2013): El inventor del peronismo. Buenos Aires, Planeta.

MOCHKOFSKY, Graciela (2011): Pecado original. Clarín, los Kirchner y la lucha por el poder. Buenos Aires, Planeta.

ORNSTEIN, Norman; MANN, Thomas (2000): The Permanent Campaign and Its Future. Washington, American Enterprise Institute.

PABLOS COELLO, José Manuel de; MATEOS MARTÍN, Concha (2004): "Estrategias informativas para acceder a un periodismo de calidad en prensa y TV". Ámbitos, 11-12.

PIZARRO, Ana; MULLER, María José; GHELFI, Lía; MITIDIERI, Valeria (2008): Periodistas y empresas. Claves de una relación necesaria. Buenos Aires, Universidad Austral.

RINCÓN, Omar (ed.) (2008): Los telepresidentes. Cerca del pueblo, lejos de la democracia. Bogotá, Centro de Competencia en Comunicación, Fundación F. Ebert.

RUIZ, Fernando (2014): Guerras mediáticas. Las grandes batallas periodísticas desde la Revolución de Mayo hasta la actualidad. Buenos Aires, Sudamericana.

SHOEMAKER, Pamel; REESE, Stephen (1996): Mediating the message. Theories of influences on mass media content. Nueva York, Longman.

SIGAL, Leon (1973): Reporters and Officials: The Organization and Politics of Newsmaking. Lexington, D. C. Heath and Company.

TÉRAMO, María Teresa (2006): Calidad informativa en los diarios regionales. Buenos Aires, Editorial de la Universidad Católica Argentina.

WAISBORD, Silvio (2000): Watchdog Journalism in South America: News, Accountability, and Democracy. New York, Columbia University Press. 
WAISBORD, Silvio (2013a): Reinventing Professionalism. Cambridge, Polity Press.

WAISBORD, Silvio (2013b): Vox populista. Medios, periodismo, democracia. Buenos Aires, Gedisa. 